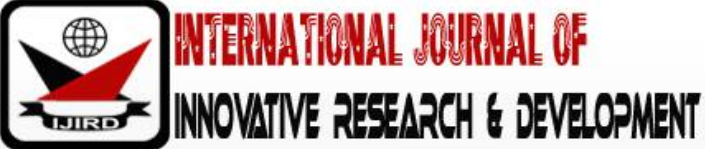

ISSN 2278 - 0211 (Online)

\section{Urban Public Spaces and Associated Environmental Challenges in Nigeria: A Review}

\author{
Azare, I.M. \\ Lecturer, Department of Environmental Science and Toxicology, Federal University, Nigeria \\ Dantata, I.J. \\ Lecturer, Department of Crop Production, Federal University Gashua, Nigeria \\ Musa, I. D \\ Lecturer, Department of Geography, Aminu Sale College of Education, Nigeria \\ Duala, $\mathbf{T}$ \\ Lecturer, Department of Geography, College of Education Azare, Nigeria
}

\begin{abstract}
:
This paper attempts to examine the broader environmental challenges affecting the establishment and utilization of urban public spaces in Nigeria. As the rate of depletion of these spaces is so alarming in the country, this work adapts the systematic review of relevant literature focusing largely on the level/ state of destruction or otherwise of urban public spaces elsewhere; with high hope of understanding and arresting/addressing the situation in Nigeria. The major findings of this work reveal that ecological zones and climatic conditions of a given area greatly influenced the state of urban public spaces in the country. However, the main challenges uncovered include; rapid urbanization, low resource base institutions or authorities, lack of priority given to the establishment and maintenance of such spaces among others. The paper finally suggests that good policies and planning; quality transport network; good drainage network; provision of healthy habitat; improved maintenance culture and opening up of more public spaces be adhered to in order to address the challenges.
\end{abstract}

Keywords: Urban, public spaces, environmental challenges, Nigeria

\section{Introduction}

Urban public spaces constitute a major environmental resource of an urban landscape. They are great public spaces serving as the living room of the city where people inhabit. They also serve as platforms which make high quality life in the cites and their suburb possible by accommodating array of public spaces that range from grand central plazas, squares and other critical infrastructure, to small, local neighborhood parks. However, urban public spaces in Nigeria are depleting at an alarming rate. The urban public spaces are particularly vulnerable in that they are immobile and infrastructure such as bridges, buildings, roads, monuments which are their critical attributes are becoming liabilities as local ecosystems that they are based on are unable to adapt to the climate-induced changes. Also, unprecedented demand for land, which resulted from rapid population increase, constitutes threat to the existing public space in many cities of the country. This paper sought to give a broad discussion on environmental challenges posed by continues destruction of urban public spaces in Nigeria, through a systematic review of relevant literature on or related to urban public spaces destruction in the country or elsewhere. According to Thompson, (2002) in Hayriye and Bulent, (2007), open spaces are described as places in cities that are used to celebrate cultural diversity, to engage with natural processes and to conserve memories. Abughazzeh, (1996) and Chitrakar, (2016) opined that public space in urban neighborhoods have meaning for people as it invites them for use and participation through creating a common platform in its provision. According to Cattell et al. (2008) and Chitrakar, (2016), public space is not just a physical setting but it also has a host of subjective meanings for its users that accumulate over time. While the provision and use of public space is changing in new neighbor hoods of the Kathmandu Valley, it remains unclear how such changes have affected residents' perception of contemporary public space and sense of community. According to Jalaladdini and Oktay, (2012) urban public space is a space within the city area which is accessible to all people and is the ground for their activity. Madanipour(1996), in Jalaladdini and Oktay, 2012, reported that urban public spaces are controlled by a public agency, and are provided and managed in the public interest". Urban public spaces could be analysed in two major forms: (a) streets; (b) squares. Urban open spaces are vital part of urban landscapes with their own set of structure and function. Natural or man-made, they contribute to the quality of life in many ways (Burke and Ewan, 1999 in Hayriye and Bulent, 2007) by providing psychological (Chiesura, 2004, in Hayriye and Bulent, 2007) and recreational (Antrop, 2000 in Hayriye and Bulent, 2007) services. 


\section{Explanation/Views}

The concept of urban open spaces is indigenous to most African traditional cities. Their planning is structured on open spaces that are permeating the urban fabric serving numerous functions ranging from socio-cultural to religious, commercial and even agricultural purposes (Abdulkarim, 2004; Arc Linus and Ugochi, 2008). In contemporary city, public space is no longer made only by canonical typologies - square, garden, public, private - but evolves several hybrid spaces and joint uses, including the sphere of communication and virtual spaces, (Pinto \& Remesar, 2012, Ana and Pedro 2017). Zhao Xiaofan, (2018) stressed that an open space in an urban setting had been described as a vacant land, either built upon or developed as gardens and recreation grounds or underdeveloped land which has value for recreational purposes, amenity, conservation and other natural resources, historic or scenic land scape or areas of outstanding natural beauty such as water bodies, valleys, hills, mountains, (Bryom, 1971; Abdulkarim, 2004; Okoli et al., 2008; Michael, 2009). Public open space' is defined as the sum of the areas of the built-up areas of cities devoted to streets and boulevards including walkways, sidewalks4, and bicycle lanes and the areas devoted to public parks, squares, recreational green areas, public playgrounds and open areas of public facilities. Public Open Space' does not include the areas devoted to public facilitiese.g. Schools, stadiums, hospitals, airports, waterworks, or military basesthat are not open to the general public. It also does not include open spaces that are in private ownership or vacant lands in private ownership. UN Human Settlements Programme (UN Habitat, 2015) Public space is the space which appears depending on the needs of citizens and it is open to the public. Feature of this space is allowing the presence of different groups of people regardless of social class, age and gender. Such spaces are much more like anexperience rather than a space, so that the result of suchinteractions and experiences among different individualsand groups will be getting a sense of collective identity, selfrespect (self-esteem), social skills and promote social participation (Zeinab, and Farah, 2012). Public open spaces accommodate a large number of everyday activities which emphasize the importance and attractiveness of the city public spaces (Gehl, 2011, Miroslava, 2016). However, Kayden (2000) in Ibama et al., (2015) shows that Public open space is defined as public or privately owned land that is publicly accessible and has been designated for leisure, play or sports or land set aside for the protection and/ or enhancement of the natural environment. According to Rajjan (2016) a term public space is a broader term that includes a range of venues for social interaction such as open spaces, streets and buildings.

Urban open spaces as natural and cultural resource, synonymous" with neither "unused Land" nor park or recreational areas; or Land or water area with its surface open to the sky, consciously acquired or publicly regulated to serve conservation and urban shaping function as well as provide recreational opportunities , (Marilyn, 1975). According Ibama et al., (2015). Public space is an integral part of the public realm. The physical public realm means the series of spaces and settings that support or facilitate public life and social interaction. It is considered as sites or settings of formal and informal public life that have 'physical' (i.e. space) and 'social' (i.e. activity) dimensions. The activities and events occurring within urban spaces can make it the socio - cultural public realm (Carmona, 2010, Mojgan, 2013). According Mojgan, (2013) Public space relates to all those parts of the built and natural environment where the public have free access. It encompasses: all the streets, squares and other rights of way, whether predominantly in residential, commercial or community/ civic uses; the open spaces and parks; and the "public-private" spaces where public access is unrestricted (at least during daylight hours). It includes the interfaces with key internal and private spaces to which the public normally has free access.

\subsection{Components of Urban Public Spaces in Nigeria}

Globally, urban areas are fastest growing land cover type with substantial portions of various continent classified as urban (UN, 2012, Collins, 2014) An urban public space is a social space that is generally open and made accessible to people. In Nigeria like in most countries, the most common components of urban public spaces includes; Roads, bridges, public squares, cinemas, parks, stadiums and public libraries, although they tend to have restricted areas and greater limits upon use. Hayriye and Bulent, (2007), identified and defined fourteen different open space categories; viz: Natural, natural drainage, agricultural, open lands, vacant, military, transportation, industry, archeological, park, canal, public, school and sport. As noted by Marilyn (1975) in Ibama et al., (2015), the Landscapes of urban open spaces can range from playing field to highly maintained environment to relatively natural landscapes. They are commonly open to public access. Ibama et al., (2015) further noted that urban open spaces may be privately owned. These include areas outside of city boundaries such as state and national parks as well as open spaces in the Countryside.

In Nigeria, most urban public spaces are owned by Government with the exception of few which are private such as cinemas, malls and buildings. In Zaria city, northern Nigeria, ten type of spaces are identified as constituting the material public space, based on analysis of typology for example from the literature and practices in Zaria, and further grouped these into 'free access' and 'quasi' public spaces reflecting degree of control and access (Garba 2007 in Shaibu, 2012) The most unique of the spaces are the "Dandali" and Neighborhood Community spaces. The "Dandali" is an informal space in front of the Emirs palace surrounded by institutional buildings, while Neighborhoods community spaces are found in the interior of residential quarters, loosely formed by houses at road intersections (Shaibu, 2012). Goomsu (2014) has come up with the proposed public spaces in Abuja as (1) National Arboretum and National Monument at the Aso Hill end of the axis, (2) Central Park in between the National Assembly Complex and the Mall , (3) Mall flanked by ministerial buildings on its two longer sides , (4) Presidential Gardens next to the Mall with the Presidential Residence in its midst and (5) Central Square or National Square at the opposite end of the axis, terminating the series of open spaces and the two diagonal parkways. 


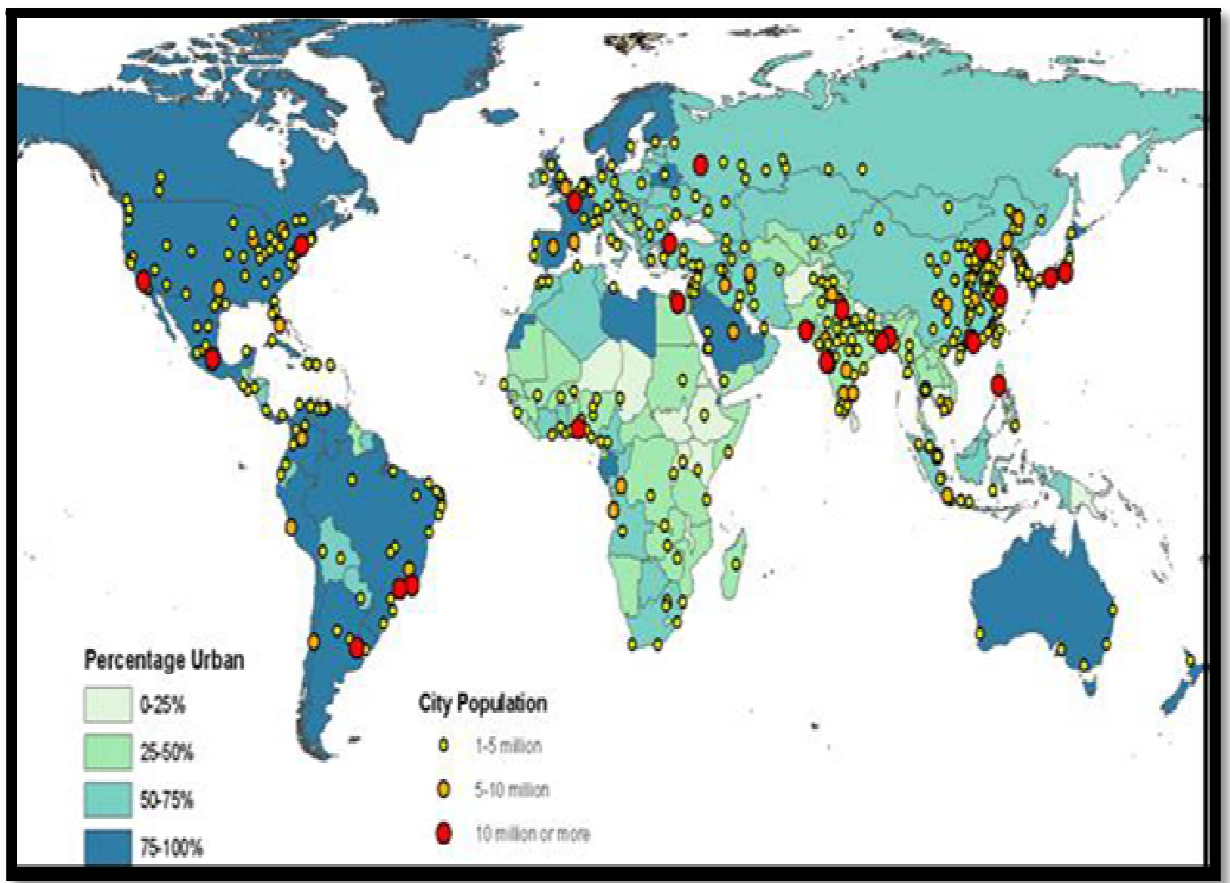

Figure 1: A Map Showing the Distribution of the World's Urban Land Coverage Source: United Nations, (2012), Collins, (2014)

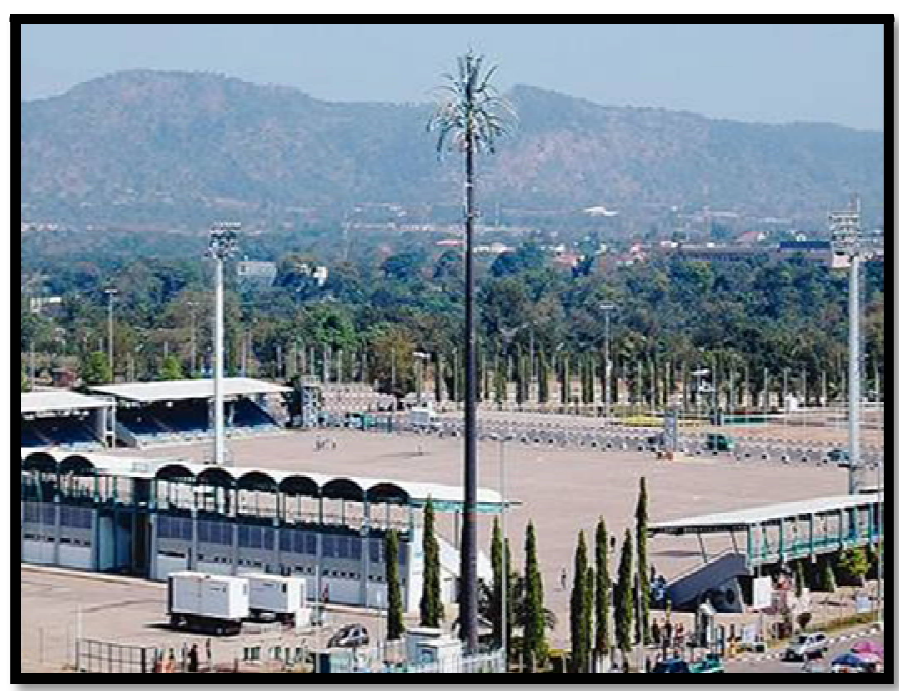

Figure 2: Eagle Square Abuja

Source: Obike, (2015) and Hajara, (2017)

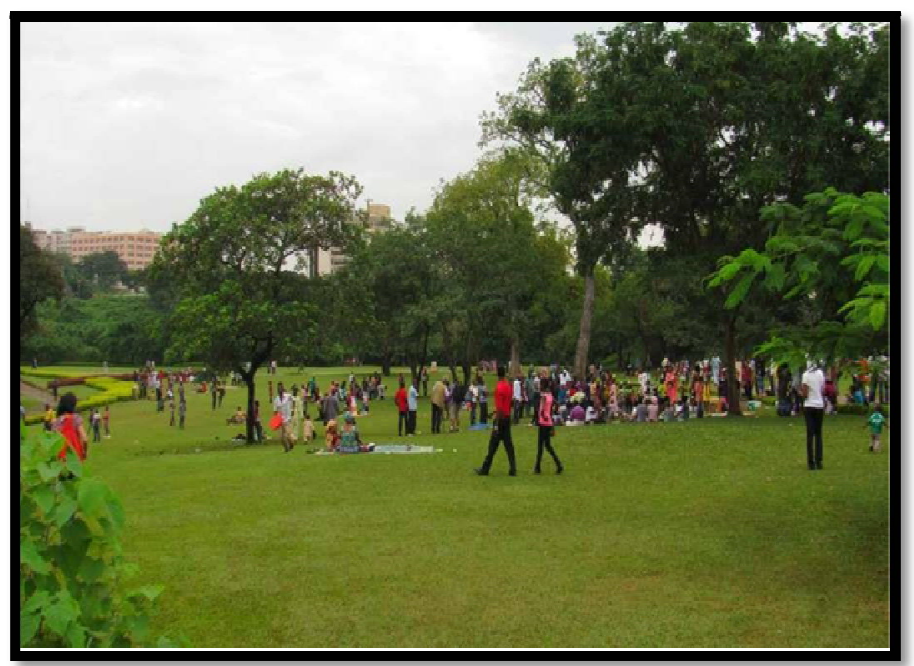

Figure 3: People Enjoying Millennium Park on Weekends Source: Hajara, (2017) 


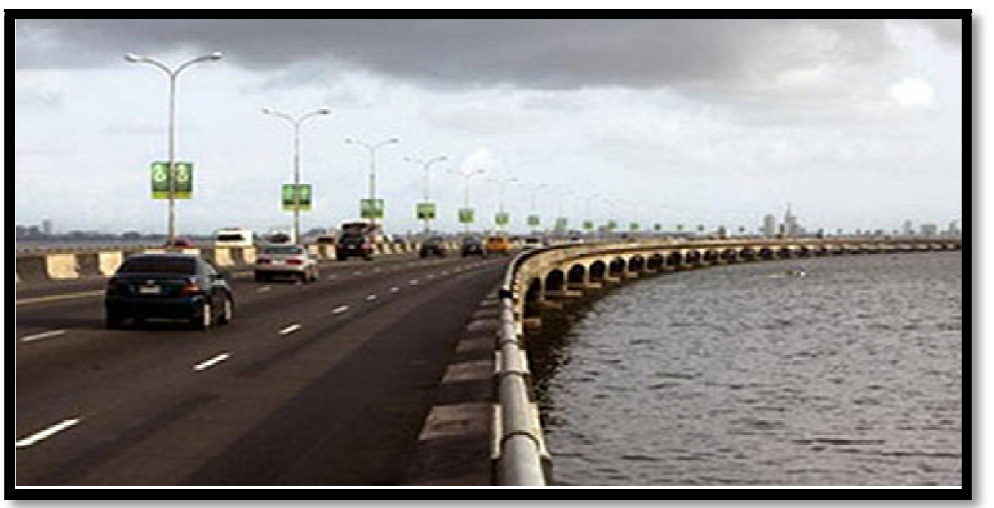

Figure 4: Third Mainland Bridge Lagos, Nigeria

Picture: 27:08:2018 Vanguard 27th August, 2018

\subsection{Adaptability of Urban Public Spaces}

Adaptability is the capacity of urban buildings, neighborhoods and spaces to adapt to changing needs. Trees and open spaces in urban areas can be successfully used to manage urban temperatures by providing shading and helping to dissipate heat through evaporation, and controlling air movement. A significant role of urban green spaces in mitigation of climate change is likely to be influencing people's behaviour so that they reduce their contribution to greenhouse gas emissions. Well planned green spaces can make cities more beautiful encouraging exercise and improving public health. As the effects of climate change become more prominent, green spaces are likely to be refuges of shade and there will be an unprecedented demand for recreational green spaces. Adaptation to climate change means making towns and cities more resilient. Well-designed, flexible public spaces are their best chance to adapt to these threats. Spaces that are softer, greener, more organic and natural will store water and are critical to modifying urban temperatures. Green spaces with a generous planting of trees link to form a network offering cooler, cleaner air. Adaptation demands that we start really understanding how our towns and cities work naturally (David, 2008)

\subsection{Urban Public Spaces, Relationship with Cities, People and the Environment (i.e. Neighborhood)}

The quality of our neighborhoods, towns and cities has a significant impact on our daily lives. Quality urban design makes a valuable contribution to our economy, our natural and built environments, and the live ability of our cities. It helps local businesses thrive. It attracts people to visit, live and work in a location. It considers the landscape, encourages biodiversity and incorporates natural ecosystems. It has an important influence on our physical and mental health and wellbeing. It provides opportunities for healthy lifestyles and community interaction, (Urban Design Protocol for Australian Cities, UDPAC, 2011). A city is usually characterized with a dense of population and it makes land use becomes more various that triggers accumulation of transportation networks. Land use and transportation network then influence how the build environment should be established and becomes the realm of public activities. People live in urban space as a container of humanity needs. Mankind as social creature has the need of social interaction with a whole range from domestic to neighborhood scale. Children need to interact with their parents and so does a wife with her husband and their relatives as well. In broader means of interaction, a person also needs to interact with his/ her friends and makes a social group (Stangor 2004; Johannes, 2014). Cities have always been the meeting point of different populations (Aristotle, 1992; Southall, 1998; Ali., 2004). Some central places, as best exemplified by the ancient agora, have acted as the meeting point of these different people. The small size of the city meant that this central public space could at the same time cater for political, economic and cultural needs, by being a place of assembly, a market place, and a place of rituals and ceremonies (Glotz, 1929; Ward-Perkins, 1974; Ali., 2004). A neighborhood can be very much a part of one's social and personal identity; (Danaë et al, 2013). Ali, 2014 reported that the neighborhood of Ano Liosia on the outskirts of Athens houses different groups of working class Greeks, immigrants, mainly from Albania, repatriated Greeks, mainly from the exSoviet Black Sea region, and Roma families. Following a recent earthquake, some rebuilding activities are taking place, although the gypsies are denied permission by the municipality to build new buildings, which has led to multi-occupancy of the existing houses. Living close to each other and to the plentiful open spaces of the area is seen as an advantage by the Roma population. However, as they feel unwanted in the neighborhood and its public spaces, they often congregate in their courtyards and inside the houses.

\subsection{Vulnerability of Urban Public Spaces as Infrastructure with Climate Change}

There have been recently warnings that the sea level is rising twice as fast as was forecasted, threatening hundreds of millions of people living in deltas, low-lying areas and small island states. But the threat of sea-level rise to cities is only one piece of the puzzle. More extreme weather patterns such as intense storms are another. Tropical cyclones and storms, in the past two years alone, have affected some 120 million people around the world, mostly in developing and least developed countries. Indeed, in some parts of the world, inland flooding is occurring more often and on a more intense basis (Mohamed, 2010). Climate change has become an inevitable global problem, affecting almost every part of the world, in which Nigeria is not left out. Various evidences in the scientific literature indicates that in the coming decades the world will witness higher temperatures and changing precipitation levels (Churkina, 2008; Akpodiogaga \& Odjugo, 2010; Chang et al., 2014; Dipeolu, 2015). Therefore, in urban areas, when the land available for housing is scarce and/ or 
unaffordable for low-income groups, the choices for location are limited. Individuals and households make choices that reflect priorities and trade-offs - for instance, with regard to location/ accessibility, availability, type of ownership (private or state owned), security (i.e. the likelihood of eviction), possibilities of service provision and regularization, and cost. In some cases, land is occupied by organizations of dwellers that select a piece of land and prepare an urban plan with plots and streets. Once settled, they struggle for services, negotiate for regularization and, where natural and environmental conditions generate risks, they demand solutions from government. Jorgelina and Gustavo (2009)

\subsection{Urban Public Spaces Policy and Management}

Management is concerned with efficiency in the conversion of opportunity and resources into wealth. It is a vital aspect of realization of set goals and objectives of any organization, institution or government especially in the case of those in charge of development of open spaces and it is the pre design stage of the park planning process for the effectiveness of the recreational area (Officha, et at., 2012) Management is concerned with the effective utilization and coordination of resource such as capital, plants, materials and labour to achieve defined (environmental) objectives with maximum efficiency (Santrock, 2007; Basorun and Ayeni; 2013). In Nigeria public acquisition of land for landscaping and open space management shows that since the mid-1950s there has been a growing interest in recreation, conservation of public open spaces, pollution abatement and myriad of other ways to improve the quality of the environment. Further there has been an increasing demand for recreational public open spaces for leisure and its related activities (Falade, 1998) Good management is a vital aspect in the realization of set goals and objectives of any organization, institution or government especially in the case of those in charge of development of open space. It demands the need, aspiration and interests of people to be served is taken into consideration. Planning is for the people and recreation must be built around the desires and interests of the people for effective participation on the park and its users (Butler, 1940, Officha, et at., 2013). Management extends to the relationship between employers and the public in order to accomplish their set purpose. They must be one in mind and purpose. Poor relationship result in lack of enthusiasm to work, indifference in a half heated effort, and labor unrest. This will result in failure to understand the motives that makes man work, such as hopes and ambition (Officha, et al, 2013)

\subsection{Environmental Challenges facing Urban Public Spaces}

Despite the various social and economic importance of public urban spaces, this paper attempts to identifies the environmental challenges associated with continues destruction of these spaces. These challenges include; increase temperature in the cities a surban heat islands, increase atmospheric pollution or carbon emission, urban flooding, unhealthy habitat, increase wind storm and excessive erosion and poor transportation network. The loss or disruption of environmentally sensitive areas, such as critical natural habitats (e.g., wetlands, wildlife corridors), reductions in open space, increased flood risks, and overall reductions in quality of life (Kenworthy \& Laube, 1999; Hirschhorn, 2001; Kahn, 2000; Brody, 2013).City park alliance reported that the urban green spaces transport and store,storm water runoff that could otherwise overpower city sewer systems causing costly flood damage and environmental pollution (ud).

The poor quality of the Nigeria urban environment has been attributed partly to the inadequate, misuse and mismanagement of the urban open spaces. This, in the opinion of Fadamiro (2002a, 2002c) and Basorun, and Ayeni, (2013) has exerted a major strain on the physical outlook of the environment and a negative effect on the welfare and productivity of the residents. The road network in many parts of the city are poorly articulated, reducing the traffic routes options available to motorists. Efficient flow of traffic is often interrupted by accidents especially where the street designs is of grid-iron pattern. This problem is aggravated by the lack of coordination between federal, state and local council road networks which result in the existence of sharp break in road quality and maintenance standard (Mabogunje, 2008, Basorun, and Ayeni, 2013).

However, urban public spaces in Nigeria are depleting at an alarming rate. The urban public spaces are particularly vulnerable in that they are immobile and infrastructure such as bridges, buildings, roads, monuments which are critical attributes of urban places are becoming liabilities due to local ecosystems that they are based on are unable to adapt to the climate-induced changes. It was also reported that Colonial rulers built and ensured that ample public open spaces and recreation parks were created. The aesthetic condition of these reserved areas brought their residents very close to nature. They (residents) had places to unwind either at weekends or at the end of each day's work. Planners took a cue from this and created public open spaces for recreation and meetings in new estates scattered all over the country.The advent of military dictatorship in the country however brought about a reign of lawlessness, the massive destruction of these open spaces and their allocation to themselves and their cronies. The civilians who took over from them in 1999 continued this wanton disregard of existing master-plans. (Vanguard, 14, May, 2007). In a related development, a study on urban sprawl in Abuja (the capital city of Nigeria) and its effect on the natural vegetation cover showed a considerable loss of the natural vegetation to the expansion of settlements. Specifically, the study revealed that in 2001 built-up areas covered 30.51 per cent of the total land area of Abuja whilst that of the natural vegetation was 21 per cent. However, in 2006 the coverage of the built-up areas increased to 42.6 per cent whilst in contrast that of the natural vegetation (green spaces) decreased to 12.19 per cent as a result of increase in urban sprawl to contain the high population growth of the city (Fanan, et, al., 2011;Collins, 2014). Also, Adedeji and Eziyi (2010) attributed urban sprawl to absence of updated master plans; uncoordinated spatial urban growth; decay of inner cities; land speculation and rapidly growing urban population lead to depletion of green areas and open spaces resulting in the loss of biodiversity, air pollution and traffic congestion due to increasing use of private automobiles. There is also the issue of incompatible land use due to lack of planning and haphazard developments. 


\section{Remedies and Ways Forward}

- $\quad$ Good policies and planning should be designated and implemented - Proficient design of urban public spaces should be made and effectively put in place. This can be aided by good policies and planning which guides the proper utilization of these places. Effective planning and policies towards safeguarding the creation and utilization of the urban public spaces should be done. This will greatly help in maintaining the existence and development of such places (urban public spaces). Laws curtailing the misuse and or alteration of these spaces should be established and properly observed.

- Quality transport network should be provided and maintained. Good transport network is so vital to the running of urban public spaces. Accessibility is largely attained by quality transport network. Such places can be well established and maintained only with quality transport system. The realization of efficient utilization of urban public spaces by the people is attained only when there is good transportation network linking the areas and people.

- There is also need for good drainage system. The existence and maintenance of the urban public spaces rely upon good drainage network or system capable of reducing the rate of environmental destruction especially that caused by the activities of water. The urban public spaces will be safe with good drainage systemand their beauty will be captured hence attracting people to patronize.

- $\quad$ Provision of healthy habitat. When people are living in a place, there should be made available all the necessary instruments/ facilities that keep such place safe from unhealthy conditions. Urban public spaces therefore must be healthy habitats capable of supporting lives and protecting their state of health. The agents responsible for the provision of healthy habitat should do about all they could to ensure urban public spaces are always clean and tidy free from all forms of contaminants. This can be achieved through engaging cleaners with proper but frequent supervision to ensure cleanness is maintained.

- $\quad$ The need to open up more spaces by both public and private enterprises. Both public and private entrepreneurs should be encouraged to create and develop more of such spaces so as to reduce pressure on the existing ones and to increase access for other utilizers. This if properly done would facilitate the advancement of urban public spaces in particular and the state in general.

- Improved maintenance of the existing urban public spaces - The existing urban public spaces need to be proficiently checked and improved maintenance culture adopted. Proper and frequent supervision of these spaces will in turn lead to continuity free of undesirable occurrences. Improved culture for the maintenance of these spaces is desirable for the safe - keeping and development of such areas.

\section{Conclusion}

Urban public spaces constitute a major environmental resource of an urban landscape. It is the platform that makes high quality life in the city and its suburb possible by accommodating array of public spaces that range from grand central plazas, squares and other critical infrastructure, to small, local neighborhood parks. However, in Nigeria despite the various social and economic importance of public urban space, they are still depleting at an alarming rate. This paper identifies increase temperature in the cities and urban heat island, increase atmospheric pollution or carbon emission, urban flooding, unhealthy habitat, increase wind storm and excessive erosion as well as poor transportation network among others as some of the major environmental challenges associated with continues destruction of these spaces. It recommends that policy planning and implementation, good transport network, proper drainages, creation and maintenance of healthy habitats and public campaign/ enlightenment among others will help in rescuing such spaces.

\section{References}

i. Adedeji, D., and Eziyi O. I. (2010): Urban Environmental Problems in Nigeria: Implications for Sustainable Development. Journal of Sustainable Development in Africa (Volume 12, No.1, 2010)

ii. Ali M. (2014): Marginal Public Spaces in European Cities. Journal of Urban Design Vol. 9. No. 3, Pp.267-286, October 2004.

iii. Ana L. B., and Pedro, B. (2017): Public Space, Infrastructure, And Landscape: an interdisciplinary matrix for urban spatial continuity. The Journal of Public Space

iv. 2017 | Vol. 2 n. 1. Available at https:/ / www.journalpublicspace.org

v. Arc Linus O. Asikogu and Ugochi A. Asikogu (2008): The Imperative of Open Spaces and Recreation Parks in the Master Plan of a City. Journal of Research in National Development Volume 6 No 2, December, 2008

vi. Basorun, J. O. and Ayeni, D.A (2013): Planning and Restoration of Environmental Values in Nigeria Dysfunctional Societies. European Journal of Sustainable Development (2013), 2, 4, 185-198

vii. Brody, S. (2013) The Characteristics, Causes, and Consequences of Sprawling Development Patterns in the United States. Nature Education Knowledge 4(5):2

viii. CIRIA open space (2018): Opportunities for previously developed land available at http:/ / www.opengreenspace.com

ix. City Park Alliance (Undated) https:// www.cityparksalliance.org/ why-urban-parks-matter/ environmental-value Environmental Value

x. Collins, A.M. (2014): Nature and Challenges of Urban Green Spaces in Africa. Centre for Urban \& Regional Studies (Univ. of Birmingham, UK) \&Dept. of Geography \& Reg. Planning (Univ. of Cape Coast, Ghana)

xi. David, T., (2008): Public Space Lessons Adapting public space to climate change. Produce on behalf of CABE space by Horticulture week July, 2008. 
xii. Danaë S. F., Tim J., Eamonn O., and Alan P. (2013): My neighborhood: Studying perceptions of urban space and neighbourhood with moblogging. Pervasive and Mobile Computing 9 (2013) 722-737. Journal homepage: www.elsevier.com/ locate/ pmc

xiii. Dipeolu, A.A. (2015): Influence of Urban Environmental Greening on Climate Change Challenges in Nigeria. Journal of Sustainable Development; Vol. 8, No. 6; 2015 ISSN 1913-9063 E-ISSN 1913-9071

xiv. Falade J.B. (1998): Public Acquisition of land for lands capping and open space management Journal of Nigeria Institute of Town Planners Vol. xi.

xv. Goomsu, I. (2014): The City as Public Space: Abuja - the Capital City of Nigeria Postgraduate Researcher University of Newcastle upon Tyne, UK FORUM Vol. 6, Issue 1, 2004.

xvi. Hajara, B. M (2017): Public Green Space in Twentieth Century Post-Colonial Capital Cities: A Case Study of Abuja. Unpublished Master's thesis. Izmir University of Economics

xvii. Hayriye, E., and Bulent, D. (2007): Effects of Land Use Development on Urban Open Spaces. Journal of Applied Sciences, 7: 1138-1144. DOI:10.3923/ jas.2007.1138.1144

URL:https:/ / scialert.net/ abstract/ ?doi=jas.2007.1138.1144

Johannes, P.S. (2014): Assessment Of Public Space Quality Using Good Public Space Index(Case study of Merjosari Sub District, Municipality of Malang, Indonesia) Procedia - Social and Behavioral Sciences 135 ( 2014 ) 10 - 17 Available online at www.sciencedirect.com

xviii. Jorgelina, Hand Gustavo, P. (2009): Environment \& Urbanization Copyright ( $) 2009$ International Institute for Environment and Development (IIED). Vol 21(1): 203-224. DOI: 10.1177/0956247809103019 www.sagepublications.com

xix. Ibama B., Wocha C., and K. B. (2015): Assessing the Use and Adequacy of Public Open Spaces in Old Port Harcourt Township. International Journal of Scientific \& Engineering Research, Volume 6, Issue 6, June-2015 657 ISSN 2229-5518

xx. Michael, O. A. (2009): Revitalizing urban public open spaces, though, vegetative enclaves in Lokoja, Nigeria. Journal of Geography and Regional Planning Vol. 2(3), pp. 051-054, March, 2009 Available online at http:/ / www.academicjournals.org/ JGRP ISSN 2070-1845

xxi. Miroslava V (2016): A Typological Classification of Neighborhood Public Open Spaces: a case Study of Novi Grad Podgorica. Facta Universitatis Series: Architecture and Civil Engineering Vol. 14, No 1, 2016, pp. 111 - 121 DOI: 10.2298/ FUACE1601111V

xxii. Mohamed El Sioufi, (2010): Climate Change and Sustainable Cities: Major Challenges Facing Cities and Urban Settlements in the Coming Decades. UN-HABITAT International Federation of Surveyors Article of the Month June 2010

xxiii. Mojgan R. (2013): Analysis of Activity Patterns and Design Features Relationships in Urban Public Spaces Using Direct Field Observations, Activity Maps and GIS Analysis Mel Lastman Square in Toronto as a Case Study. Unpublished Master Thesis University of Waterloo

xxiv. Officha, M.C., Onwuemesi, F.E. and Akanwa, A.O. (2012): Problems and Prospect of Open Spaces Management in Nigeria: World Journal of Environmental Biosciences. Available Online at: www.environmentaljournals.org Volume 2, Issue 1: 7-12

xxv. Officha, M.C., Onwuemesi, F.E., Enete, I.C.; and Nzeamalu, I.C (2013): Assessing the Need for Developing and Managing Recreational Facilities in Nigeria. IOSR Journal of Environmental Science, Toxicology and Food Technology (IOSR-JESTFT) e-ISSN: 2319-2402, p- ISSN: 2319-2399. Volume 3, Issue 1 (Jan. - Feb. 2013), PP 26-29 www.Iosrjournals.Org

xxvi. Rajjan Chitrakar, (2016): Meaning of public space and sense of community: The case of new neighbourhoods in the Kathmandu Valley. International Journal of Architectural Research. Available online at https:/ / www.researchgate.net/ publication/ 301651015

xxvii. Shaibu B. G. (2012): Diversity in the Public Space of a Traditional City - Zaria, Nigeria. ReasearchGate. Available online at https:/ / www.researchgate.net/ publication/ 275949118

xxviii. Siavash Jalaladdini and Derya Oktay, (2012): Urban Public Spaces and Vitality: A Socio-Spatial Analysis in the Streets of Cypriot Towns. Asia Pacific International Conference on Environment-Behaviour Studies, Salamis Bay Conti Resort Hotel, Famagusta, North Cyprus, 7-9 December 2011 Available online at Available online at www.sciencedirect.com

xxix. UDPAC, (2011): Creating Places for People. An Urban Design Protocol for Australian Cities, November, 2011

xxx. UN Habitat, (2015): Adequate Open Public Space in Cities a Human Settlements Indicator for Monitoring the Post2015 Sustainable Development Agenda. A Presentation of the UN Human Settlements Programme (UN Habitat) at the Expert Group Meeting on the Indicator framework for the post-2015 development agenda, New York City, 2526 February 2015.

xxxi. Zeinab, J. A. and Farah, H. (2012): Urban public space designing criteria for vulnerable groups

xxxii. (Women and children). Canadian Journal on Environmental, Construction and Civil Engineering Vol. 3, No. 4, May 2012

xxxiii. Zhao Xiaofan, J. Y. (2018): The urban public space betterment and land use sustainability under the human behavior: IOP Conf. Series: Earth and Environmental Science 113(2018) 012143. 